\title{
International medical graduates in the National Health Service
}

\author{
Amit Malik ${ }^{1}$ and Greg Lydall ${ }^{2}$
}

${ }^{1}$ Consultant Psychiatrist, Hampshire Partnership NHS Trust; Correspondence Editor, International Psychiatry, email ip@rcpsych.ac.uk ${ }^{2}$ Specialty Registrar (ST4) in General Adult Psychiatry, Highgate Mental Health Centre, Dartmouth Park Hill, London, UK

\begin{abstract}
he UK's National Health Service (NHS) has benefited from the skills of foreign qualified doctors for many years. International medical graduates (IMGs) - that is, those doctors with primary medical qualifications outside the European Economic Area (EEA) - have come to the UK despite the significant personal and financial costs, alongside the burden of taking the Professional and Linguistic Assessment Board (PLAB) examination. Despite the costs and increasing indications that the UK job market was becoming saturated with the increased indigenous medical school output and expansion of the EEA, doctors still migrate to the UK in their thousands (McGinn, 2005). The government's active international recruitment policy, which continued until very recently despite the significant increase in places in UK medical schools, was partially responsible for this trend. Until last year, once registered to practise in the UK, access to specialty training was facilitated by the permit-free training visa (PFTV) system, which allowed IMGs to work and train simultaneously, without the need for a work permit. This meant that they could compete on an equal footing with UK graduates for training opportunities in the UK. The implementation and potential impact of some of the recent policy changes in the NHS specifically with regard to IMGs is discussed here briefly.
\end{abstract}

\section{Changes to immigration rules}

On 3 April 2006, without warning, the UK government announced that the provision of permit-free training would be withdrawn within the short period of a month and that all IMGs wishing to pursue postgraduate training beyond their current visa would have to apply for either a work permit (which meant that they could access training opportunities only for which there were no appointable EEA nationals) or the points-based Highly Skilled Migrant Programme (HSMP), which was contingent on a variety of factors, including qualifications and previous salary. The work permit route was complicated by the worsening employment situation within postgraduate training, leading to the likelihood that EEA nationals in preference to IMGs would fill most training posts. The HSMP provision, besides discriminating against those in the early stages of their training, also was made unfair by the stipulation that the length of the leave to remain granted under this programme should cover the entire duration of the training. This was most improbable given that HSMP visas are initially issued for 2 years, with a provision of further extension for 3 years, whereas all the new run-through training programmes are at least 6 years long.
The main criticism of the new immigration rules is not necessarily that they were conceived at all. It is the fact that these regulations were applied across the board, to new immigrants and those IMGs already in the UK training system, many of whom had settled with their families and had made long-term personal and career commitments to the UK. The greatest irony is that the most vulnerable group of IMGs - those who have not yet had an opportunity to reap any rewards for their struggles, in the form of either financial remuneration or prestigious UK qualifications - are the worst hit by the sudden implementation of these new regulations. A significant number of overseas doctors have taken out considerable financial loans to enable them to travel to the UK and take the PLAB examination. Many have now been left stranded without any qualifications to show for the years they have spent in training in the UK.

\section{Modernising Medical Careers}

Modernising Medical Careers (MMC) is a Department of Health initiative to transform and streamline the way postgraduate medical training is structured and delivered (Department of Health, 2004). Many concerns have been expressed about rapidly implementing an excessively rigid and bureaucratic system and the risks this could pose to patient care and service delivery. Even greater concerns were expressed by many of the stakeholders about the computerbased national selection process called the Medical Training Application Service (MTAS) that was being hurriedly implemented without being piloted for validity, reliability, feasibility and acceptability. The failures that have resulted from this system have been widely reported in both the medical and the general press and will not be rehearsed here.

As the national selection process was due to be implemented soon after the new immigration regulations were brought into force, it meant that all trainees at the level of senior house officer would have to apply again for their own jobs - this time under the new visa regulations.

Throughout the development and implementation of MTAS, the rules with regard to IMG applicants, especially HSMP holders, were unclear. This caused great anxiety among immigrant doctors in the UK. It remained unclear until the very last moment before applications opened whether HSMP holders would be considered equivalent to EEA nationals. Official advice remained unclear regarding the length of HSMP required to apply for run-through programmes. Some ambiguity also existed about whether these HSMP holders could even apply for specialty training through MTAS. It was 
understood that those without HSMPs would be considered for specialty training posts via the work permit route only if there were no eligible EEA nationals applying for them. As mentioned above, this especially had implications for those early on in their training and not yet eligible for a HSMP visa application.

\section{Mental health of IMGs}

There is little published evidence regarding the mental health of UK junior doctors in general and more specifically IMGs. Doctors are known to be at increased risk of stress, mental illness, substance misuse and suicide, compared with other professionals and the general population (Ghodse et al, 2000; Tyssen \& Vaglum, 2002). In addition, immigration is thought to be a risk factor for mental illness and suicide (Bhugra \& Jones, 2001). The significant financial debts incurred by many IMGs, combined with poor job prospects, loss of control and the possibility of discrimination may be further stressors in an already vulnerable group.

Preliminary results of an online survey regarding the mental health of MTAS applicants conducted by the authors suggest the adverse impact of the recent changes in postgraduate medical selection and training on all UK junior doctors (Lydall et al, 2007). The final results of the survey, which had 191 IMGs among its 1002 respondents, will be published as soon as the analysis is completed.

\section{Conclusions}

Immigrant doctors have traditionally provided invaluable services to the NHS since its inception. The manner in which changes have been implemented in the past year can be characterised as inept, at best. Thousands of immigrant doctors who came to the UK to work in a fair and equitable system have been betrayed by the abrupt change in immigration regulations after they made the effort and investment to come to work in the NHS. The disregard for this group of medical professionals has been made worse by a lack of consideration for IMGs during the constant evolution of the rules during the implementation of and in response to the MTAS debacle.

The commoditisation of overseas doctors by the UK system will have long-term consequences for recruitment, especially in shortage specialties like psychiatry. There are also bound to be serious implications for the mental health not only of those IMGs who have been affected but also of all other IMGs working in the UK, as well as their UK-trained colleagues. If the NHS continues to treat its highly valued and committed front-line staff with such disregard, it is only a matter of time before all that are left are insensitive centralised policy-makers and no one to deliver either their policies or, more importantly, high-quality healthcare.

\section{References}

Bhugra, D. \& Jones, P. (2001) Migration and mental illness. Advances in Psychiatric Treatment, 7, 216-222.

Department of Health (2004) Modernising Medical Careers: The Next Steps. See http://www.mmc.nhs.uk/download/The-next-steps.pdf (last accessed August 2007).

Ghodse, A. H., Mann, S. \& Johnson, P. (2000) Doctors and Their Health. Read Healthcare Publishing.

Lydall, G. J., Malik, A. \& Bhugra, D. (2007) Mental health of applicants seems to be deteriorating. BMJ, 334, 1335

McGinn, K. (2005) PLAB: key to the kingdom. StudentBMJ, 13, 468.

Tyssen, R. \& Vaglum, P. (2002) Mental health problems among young doctors: an updated review of prospective studies. Harvard Review of Psychiatry, 10, 154-165.

\section{Traditional healers}

\section{David Skuse}

Behavioural and Brain Sciences Unit, Institute of Child Health, London WC1 1EH, UK, email d.skuse@ich.ucl.ac.uk

\begin{abstract}
rad raditional healers are an important source of psychiatric support in many parts of the world, including Africa. They offer a parallel system of belief to conventional medicine regarding the origins, and hence the appropriate treatment of, mental health problems. In this issue we present a thematic review from three regions of Africa where traditional healers are still important - and probably far more numerous than psychiatrists trained in Western medicine. First, we discuss South Africa, in a report from Professor Tuviah Zabow. Some years ago it was estimated that there were nearly ten times as many traditional healers practising in that country as there were doctors trained in modern medicine (Kale, 1995). The prevailing justification for their interventions, according to traditional beliefs, is that disease is a supernatural phenomenon. Its manifestations are
\end{abstract}

governed by a hierarchy of vital powers. At the apex of this hierarchy is a deity of greatest power, followed by lesser spiritual entities, ancestral spirits, living persons, animals, plants and then objects (Kale, 1995). These entities interact and, should they become disharmonious, illness could be caused. Harmony can, however, be restored through judicious intervention, provided by a suitably trained person who treats the patient holistically, within the context of their family and their community.

In his article, Professor Zabow emphasises that indigenous healers may be regarded as falling into three broad categories: diviners (the majority of whom are female and selected by their ancestors to this calling); herbalists; and faith or spiritual healers (usually within the Christian tradition). South Africa is trying to regulate the activities of 